\title{
Three-dimensional magnetization vector inversion of a seamount
}

\author{
Ryuji Kubota and Akinori Uchiyama \\ Kawasaki Geological Engineering Co. Ltd., 2-11-15 Mita, Minatoku, Tokyo 108-8337, Japan
}

(Received February 16, 2004; Revised July 14, 2005; Accepted August 1, 2005)

\begin{abstract}
A three-dimensional non-uniform magnetic modeling is proposed to obtain information about a magnetization of a seamount, which was divided into many blocks modeled by layered and rectangular prisms, and parameters were assigned to each block describing magnetic three components. Our data were the magnetic total force on the sea. A set of linear observation equations was formulated in terms of three components of magnetization for each block. The solution was obtained by using the conjugate gradients method because of its fast and accurate advantages of calculation. In this inversion, a common set of three components was defined for several blocks to decrease the number of unknown parameters. A computer program has been tested with artificial data and applied to data of Daiichi Kashima Seamount observed during the first phase of the Kaiko project carried out with the $\mathrm{R} / \mathrm{V}$ Jean Charcot in 1984. In the real application, the crustal structure was divided into three layers (top depth to $5 \mathrm{~km}$ depth, 5-6.5 km depth and 6.5-8 km depth). The result of the inversion shows that the top portion and the submerged western half of this seamount are covered with the low magnetization layers, and in the middle layer (5-6.5 km depth) of eastern half side, declinations, inclinations and intensities are almost northward, $15^{\circ}$ and 3-5 $\mathrm{A} / \mathrm{m}$, respectively. In the third layer $(6.5-8 \mathrm{~km}$ depth), the reverse magnetizations are revealed in the southeastern and northern sides of Daiichi Kashima Seamount and around Katori Seamount. These reverse magnetizations may reflect part of the magnetic lineations of the Pacific plate.
\end{abstract}

Key words: Magnetization vector, magnetic modeling, non-uniform magnetization.

\section{Introduction}

Seamount paleomagnetism is of particular interest and importance in the study of paleomagnetic field and oceanic plate motions, because it is extremely difficult to obtain fully-oriented samples from the oceans for laboratory paleomagnetic studies. However, an inversion of the magnetic anomaly of a seamount can yield essentially the same information owing to the topographic effect of the seamount body.

The observed magnetic anomaly caused by a seamount can be mathematically formulated as a linear combination of the Cartesian components of its mean magnetization vector and volume integrals of its body. Usually the volume integrals of a body of arbitrary shape is approximated by simple geometric bodies whose volume integrals can be calculated (Vacquier, 1962; Talwani, 1965). The components of the magnetization vector can then be determined through an over-determined linear least square inversion.

On the other hand, Parker et al. (1987) developed a linear inverse theory in Hilbert space to calculate a magnetization model by maximizing the uniform part (semi-norm minimization). This theory is useful for calculating three dimensional non-uniform magnetization vectors using observations of the magnetic field anomaly and bathymetric contour of a seamount, and accounts for the complicated shape of seamounts, representing the body by a covering of triangular facets.

Copyright (c) The Society of Geomagnetism and Earth, Planetary and Space Sciences (SGEPSS); The Seismological Society of Japan; The Volcanological Society of Japan; The Geodetic Society of Japan; The Japanese Society for Planetary Sciences; TERRAPUB.
Recently, the idea of a geomagnetic tomography by modeling a three dimensional body with layered and segmented blocks, which have variable magnetization intensities, was first applied to the Quaternary volcano of Miyake-jima island in Japan by Ueda et al. (2001). This method is based on a simple linear inverse theory compared with the theory by Parker et al. (1987). In the present study, we expand the parameters of each block to three components of magnetization shown by $J x, J y, J z$ for derivation of the internal structure of magnetization direction in addition to the magnetization intensity.

We shall first test our method by using artificial data generated and examine the effectiveness of our measures for determination of non-uniform magnetizations of a seamount. We shall then apply our method to data of Daiichi Kashima Seamount observed during the first phase of the Kaiko project carried out with the R/V Jean Charcot in 1984 (Kaiko I Research Group, 1986).

The method can be extended in two directions by (1) increasing more realistic modeling of seamounts and by (2) separating superimposed magnetic anomalies into anomalies originated from magnetic lineations of oceanic plate and those intrinsic to the seamount.

\section{3-D Non-uniform Magnetization Vector Inver- sion}

Since the target area is small in comparison with the earth's surface area, we shall use a Cartesian coordinate system with the $Z$ axis vertically downward and we shall write the station coordinates as the station coordinates as $x_{i}$, $y_{i}$ and $z_{i}(i=1,2, \ldots, m)$. Consider a volume of the earth 

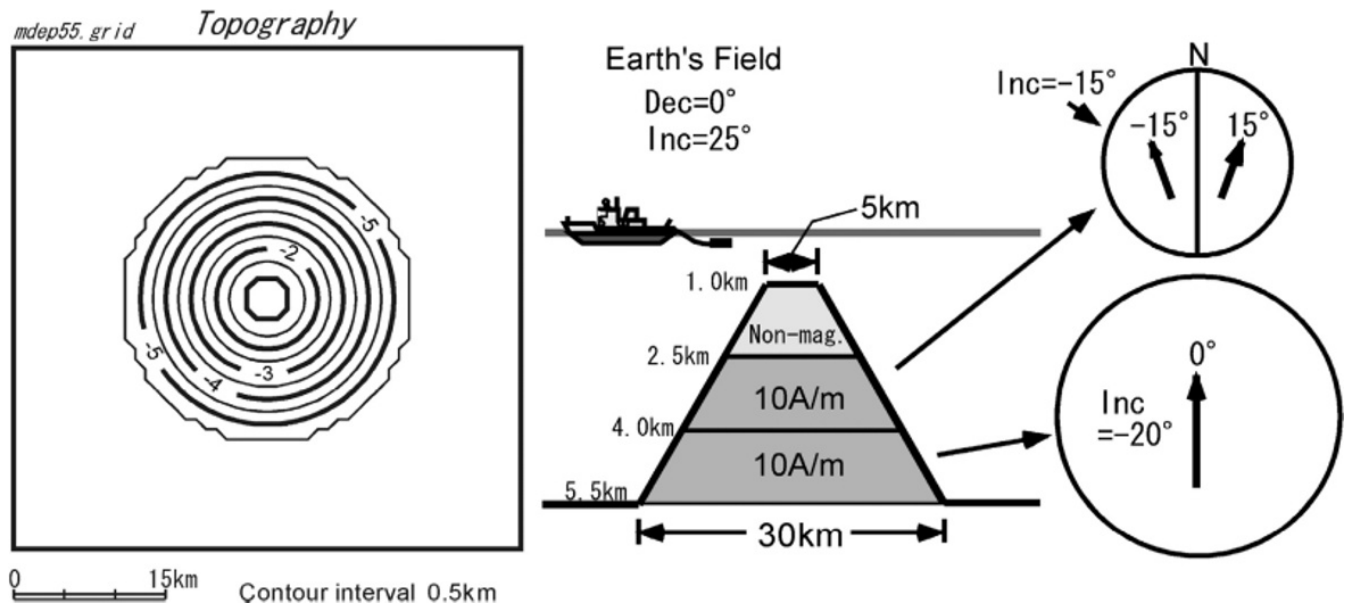

Fig. 1. Seamount model for testing the computer program of the inversion.

under the observation area and divide it into rectangular blocks with sides parallel to the $X, Y$ and $Z$ axes. A stack of rectangular prisms gives a simple way to approximate a three dimensional body. If the area is small enough, each prism can be assumed to have constant magnetization vector. Then by the principle of superposition, the magnetic anomaly of the body at any point could be approximated by summing the effects of all the prisms.

In Ueda et al. (2001), the magnetic field $T_{i}$ at the $i$-th station is given by

$$
T_{i}=m_{1} B_{i 1}+m_{2} B_{i 2}+\cdots+m_{n} B_{i n}+T_{0}+E_{i},
$$

where $m_{j}$ is the intensity of the $j$-th prism, and $B_{i j}$ is the field anomaly for the $j$-th prism $(j=1,2, \ldots, n)$ at the $i$-th station, assuming an unit magnetization in a constant direction. $T_{0}$ is the offset of a field and $E_{i}$ represents errors in observation, respectively.

The structure of a volcano is divided into many blocks modeled by layered and rectangular prisms, and parameters are assigned to each block describing magnetic intensities. The whole of observed anomalies are written as a column vector $\mathbf{T}$, with components arranged as follows:

$$
\mathbf{T}^{\mathbf{T}}=\left(T_{1}, T_{2}, T_{3}, \ldots, T_{m}\right),
$$

where $\mathbf{T}^{\mathbf{T}}$ denotes the transpose of $\mathbf{T}$. The linear observation equation is

$$
\mathbf{T}=\mathbf{B}_{\mathbf{m}}+\varepsilon,
$$

where $\mathbf{B}$ is the field anomaly matrix, $\mathbf{m}$ is the model parameter adjustment vector, and $\varepsilon$ is an error vector with components $E_{i}$, respectively.

In this study, we expand the parameters of each prism to three components of magnetization. The magnetic field $\Delta T_{i j}$ for the $j$-th prism at the $i$-th station is given by

$$
\Delta T_{i j}=J x_{j} G x_{i j}+J y_{j} G y_{i j}+J z_{j} G z_{i j},
$$

where $J x_{j}, J y_{j}$, and $J z_{j}$ are the three components of magnetization vector of the $j$-th prism, and $G x_{i j}, G y_{i j}$ and $G z_{i j}$ the field anomalies at the $i$-th station due to the $j$-th prism, assuming unit magnetizations in the $x, y$ and $z$ directions,

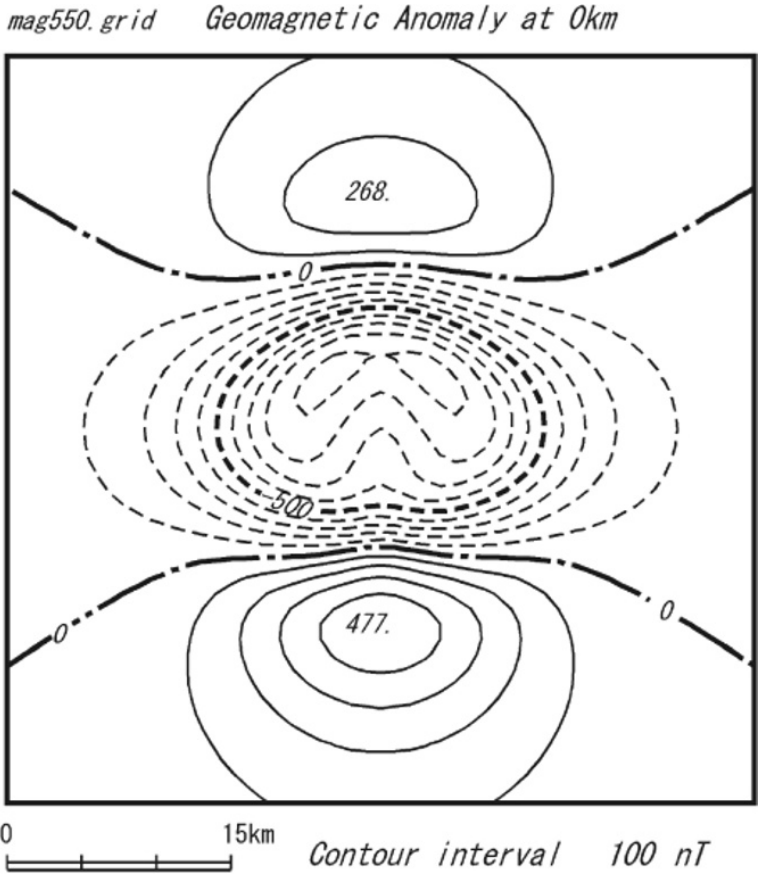

Fig. 2. Total field anomalies at the sea surface based on the seamount model in Fig. 1.

respectively. Then the observed total magnetic field $T_{i}$ of Eq. (1) is rewritten as

$$
T_{i}=\sum_{j=1}^{n} \Delta T_{i j}+T_{0}+E_{i} .
$$

A set of linear observation equations is formulated by the three components of magnetization for each block. We shall write magnetizations and the field offset parameters as a column vector $\chi$, whose components are as follows:

$$
\begin{array}{r}
\chi^{\mathbf{T}}=\left(J x_{1}, J y_{1}, J z_{1}, J x_{2}, J y_{2}, J z_{2}, \ldots,\right. \\
\left.J x_{n}, J y_{n}, J z_{n}, T_{0}\right) .
\end{array}
$$

Then equations (3) and (4) can be rewritten as

$$
\mathbf{T}=\mathbf{G} \chi+\varepsilon,
$$




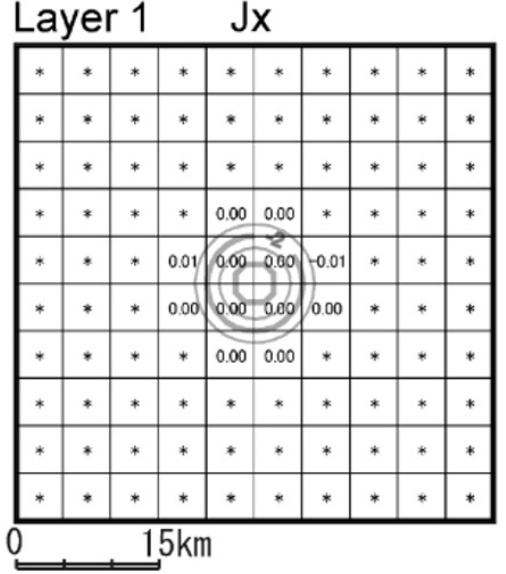

Layer $2 \mathrm{~J}(\mathrm{~A} / \mathrm{m})$

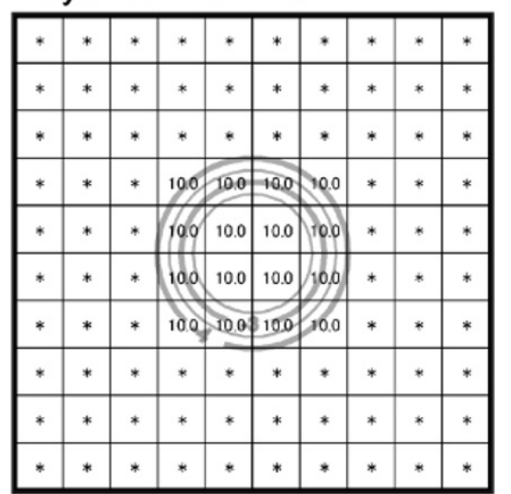

\section{Layer 3}

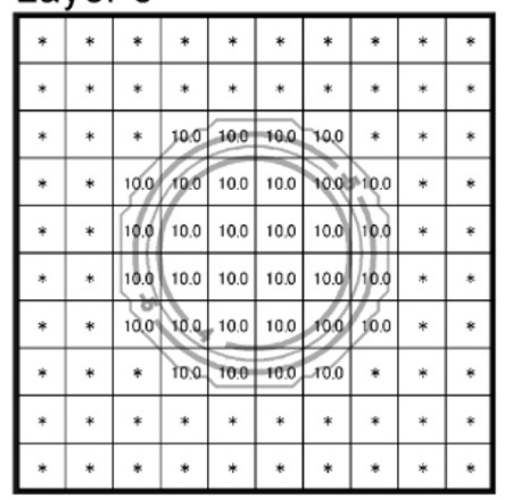

Jy

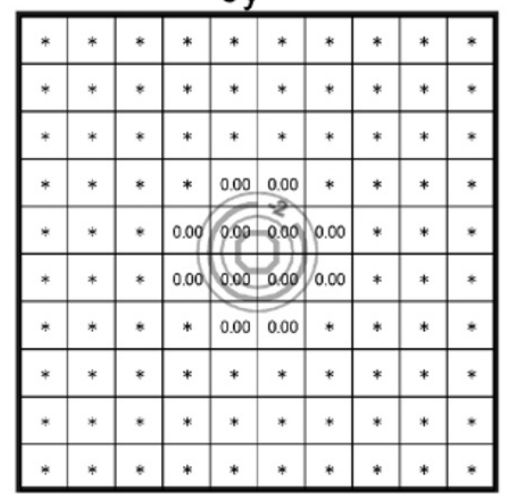

Declination(deg.)
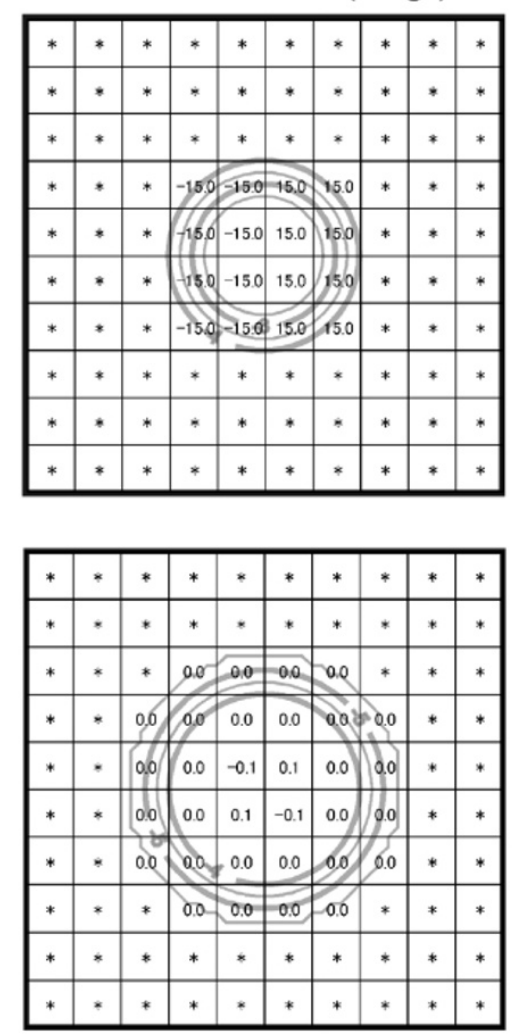

$\mathrm{Jz}$

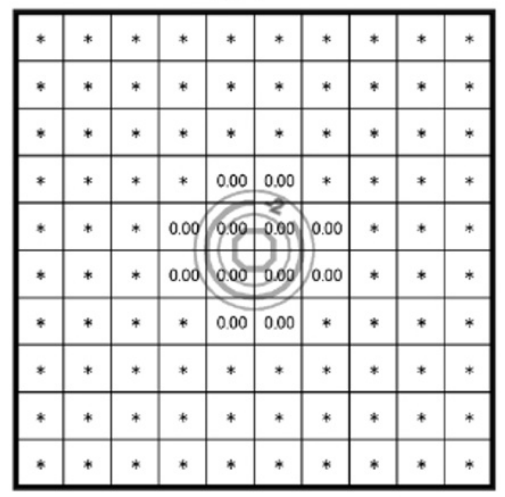

Inclination(deg.)
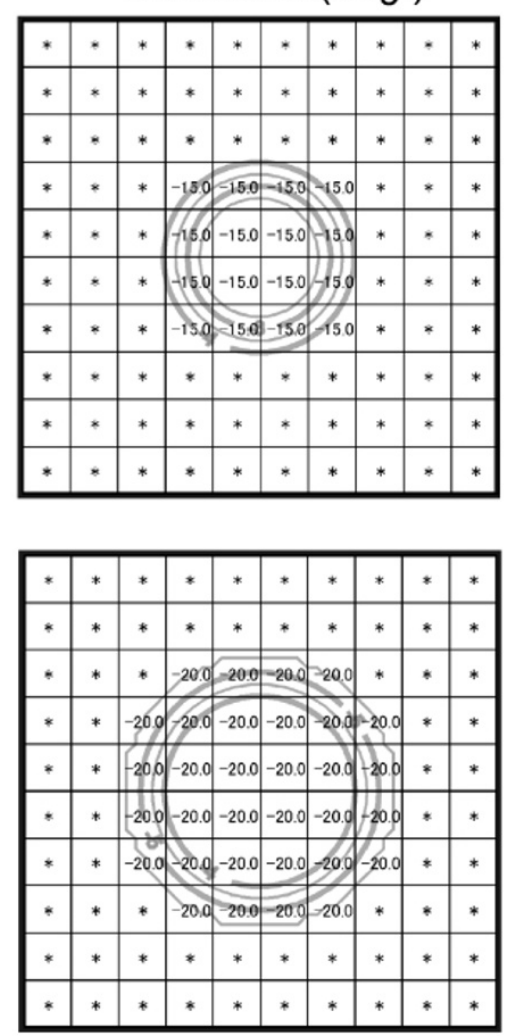

Fig. 3. Results of inversion for the total field anomalies in Fig. 2. The three components of magnetizations are shown for the top layer (layer 1), and magnetic intensities, declinations and inclinations shown for the middle (Layer 2) and bottom (Layer 3) layers. The superimposed contours are topographies for each layer.

where $\mathbf{G}$ is a $m \times(3 n+1)$ matrix with the components given by

$$
\mathbf{G}=\left[\begin{array}{cccccccc}
G x_{11} & G y_{11} & G z_{11} & \cdots & G x_{1 n} & G y_{1 n} & G z_{1 n} & 1.0 \\
G x_{21} & G y_{21} & G z_{21} & \cdots & G x_{2 n} & G y_{2 n} & G z_{2 n} & 1.0 \\
& \vdots \\
G x_{m 1} & G y_{m 1} & G z_{m 1} & \cdots & G x_{m n} & G y_{m n} & G z_{m n} & 1.0
\end{array}\right]
$$

The magnetic field of a rectangular prism at the origin is given by Bhattacharyya (1964). We solve the linear equation (5) using the conjugate gradients method reported by Bjorch and Elfving (1979) because of its fast and accurate advantages of calculation as is shown by Ueda et al. (2001) and Kubota et al. (2001). In this method it is avoided to compute the normal equation. The basic algorithm is given by the following scheme using the iteration step $q$;

$$
\begin{aligned}
& \text { for } q=0 ; \chi^{(0)}=0 ; s^{(0)}=T ; r^{(0)}=\mathbf{G}^{T} \mathbf{T} ; p^{(0)}=r^{(0)} \\
& \text { for } q=0,1,2, \ldots \\
& \quad w^{(q)}=\mathbf{G} p^{(q)} \\
& \quad \alpha_{q}=\left(r^{(q)}, r^{(q)}\right) /\left(w^{(q)}, w^{(q)}\right) \\
& \quad\left[\text { where }\left(r^{(q)}, r^{(q)}\right)=\sum_{j=1}^{n}\left(r_{j}^{(q)}\right)^{2}\right] \\
& \quad \chi^{(q+1)}=\chi^{(q)}+\alpha_{q} p^{(q)} ; s^{(q+1)}=s^{(q)}-\alpha_{q} w^{(q)} \\
& \\
& r^{(q+1)} \mathbf{G}^{T} s^{(q+1)} \\
& \\
& \text { if } r^{(q+1)}<\varepsilon \text { then quit } \\
& \\
& \beta_{q}=\left(r^{(q+1)}, r^{(q+1)}\right) /\left(r^{(q)}, r^{(q)}\right) \\
& p^{(q+1)}=r^{(q+1)}+\beta_{q} p^{(q)}
\end{aligned}
$$

where $r_{j}^{(q)}$ is a component of the vector $r^{(q)}$ which corre- 


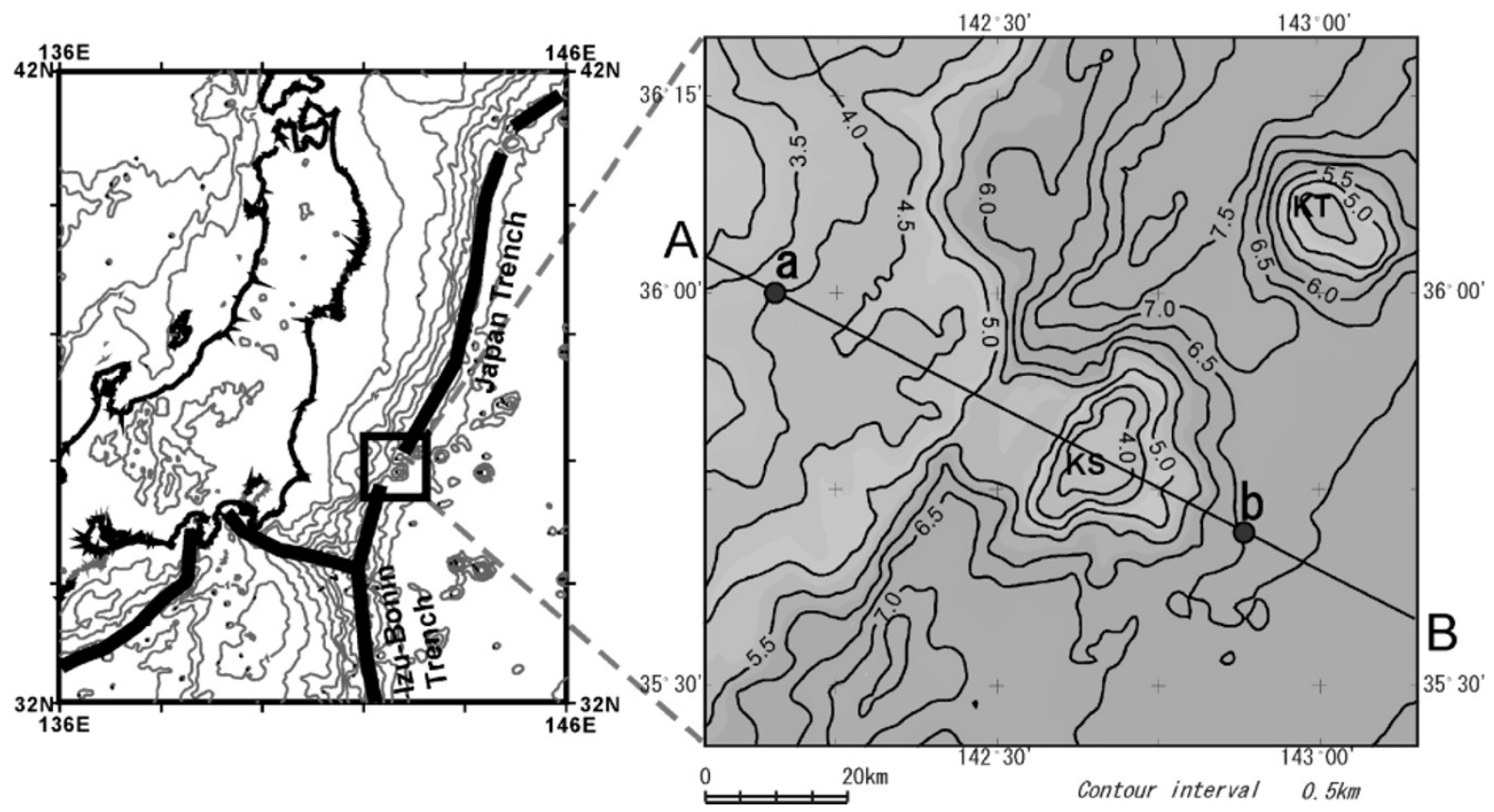

Fig. 4. Topography around Daiichi Kashima Seamount from the bathymetric data "J-EGG500" compiled by the Japan Oceanographic Data Center. KS: Daiichi Kashima, KT: Katori. The cross-sections along A-B and a-b are shown in Fig. 7 and Fig. 10 respectively.

sponds to the residual of the normal equation. Furthermore,

$$
s^{(q)}=\mathbf{T}-\mathbf{G} \chi^{(q)}
$$

is the residual in the least square system.

\section{Testing with Artificial Data}

An obvious way of testing our computer program is to apply it to an artificial data set generated by a specified model having known parameters. Figure 1 shows a seamount model formed by three horizontal layers having common thickness of $1.5 \mathrm{~km}$, in which the depth and diameter of the top are $1.0 \mathrm{~km}$ and $5.0 \mathrm{~km}$ and those of the bottom are $5.5 \mathrm{~km}$ and $30.0 \mathrm{~km}$, respectively. The top layer is nonmagnetic, and the middle and the bottom layers are magnetized as shown in Fig. 1. The inclinations are $-15^{\circ}$ in the middle and $-20^{\circ}$ in the bottom layer. The middle layer has two declinations which are $-15^{\circ}$ in the western part and $15^{\circ}$ in the eastern part. The declination in the bottom layer is northward uniformly. In this model the inclination of the earth's field is assumed to be $25^{\circ}$ and the declination to be northward.

Figure 2 indicates the total field anomalies at the sea surface based on the seamount model in Fig. 1. In this calculation, each layer was divided into rectangular blocks with the horizontal size of $1 \mathrm{~km}$ square per one block, and the grid spacing of the anomalies is $1 \mathrm{~km}$ in the north $(y)$ and the east $(x)$ directions.

On the other hand, in inverting data we define a common set of the medium parameters for several blocks in each layer to decrease the number of unknowns. In this model we adopted 5 by 5 blocks as the common area. Figure 3 indicates the results of inversion, in which the three components of magnetization are shown for the top layer and magnetic intensities, inclinations and declinations shown for the mid- dle and bottom layers. It is clear that the model parameters are reconstructed almost completely.

\section{Application to Daiichi Kashima Seamount Data}

The Kaiko project was a French-Japanese cooperative scientific effort to investigate the structures and geodynamic processes in the deep trenches surrounding Japan islands. The first phase of the Kaiko project (Kaiko I) was carried out with the R/V Jean Charcot during June and July 1984 (Le Pichon et al., 1987). The Jean Charcot complete set of data were published by Kaiko I Research Group (1986). We have selected the data of Daiichi Kashima Seamount during Leg 3 of the Kaiko I cruise for our applications of the inversion program. Daiichi Kashima Seamount is situated in the axial zone of the southernmost portion of the Japan Trench as shown in Fig. 4.

Mogi and Nishizawa (1980) first found the scarp separating Daiichi Kashima Seamount into two blocks based upon bathymetric data obtained by the Hydrographic Department, Maritime Safety Agency of Japan (JHD, present name: the Hydrographic and Oceanographic Department, Japan Coast Guard (JHOD)), and it was concluded that the western half of Daiichi Kashima Seamount had broken down at the axis of the Japan Trench following the subduction of the Pacific plate. Thereafter, Ueda (1985) suggested that magnetic anomalies over Daiichi Kashima Seamount, observed by the JHD showed a non-magnetic cap in both the top portion and the submerged western half part of the seamount and reflected the downward vertical offset of the western half. Other studies concerned with this seamount were reviewed by Kobayashi et al. (1987).

The total magnetic anomalies by $\mathrm{R} / \mathrm{V}$ Jean Charcot are shown in Fig. 5(a), where the mapping area is $80 \mathrm{~km}$ by 80 $\mathrm{km}$ and the grid spacing $2.5 \mathrm{~km}$ in the north and east directions. Furthermore, in order to avoid an under-determined 


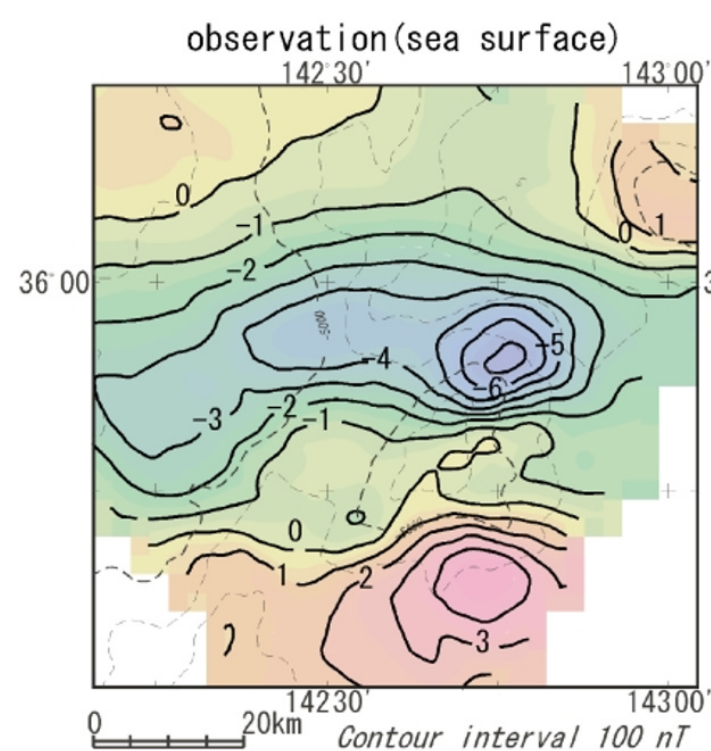

(a)

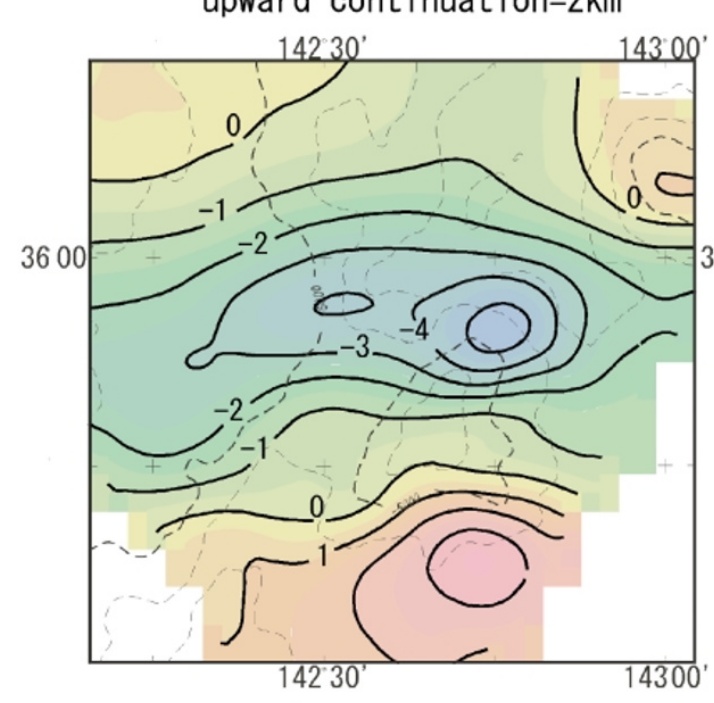

(c)

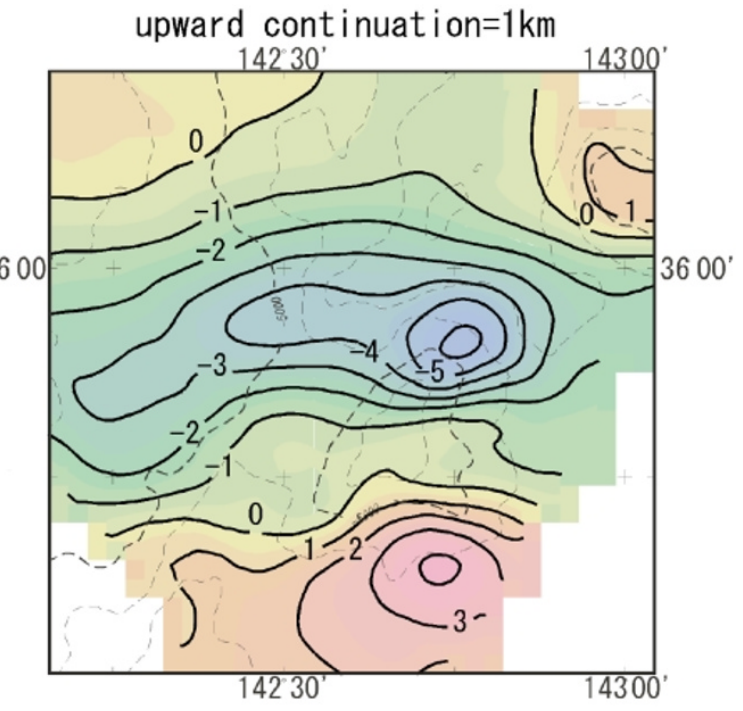

(b) upward continuation $=5 \mathrm{~km}$

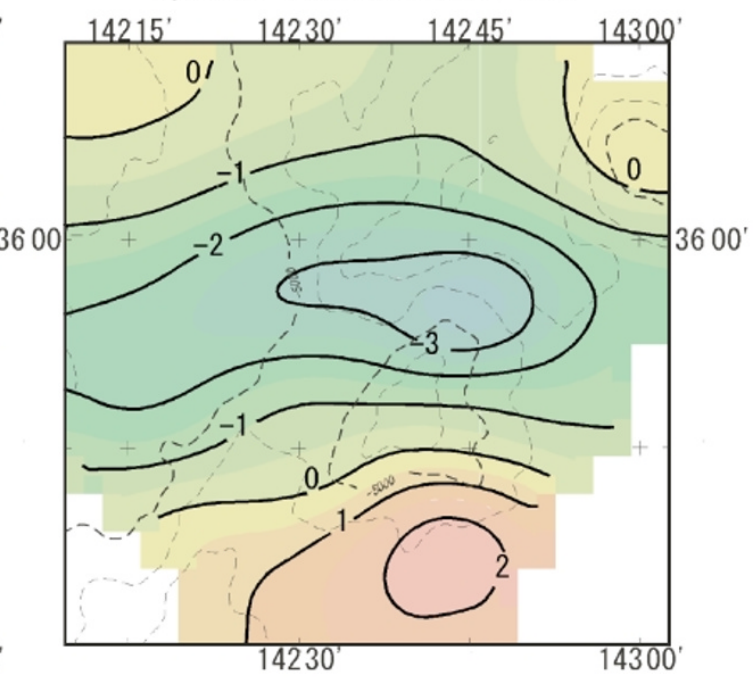

(d)

Fig. 5. Total magnetic anomalies around Daiichi Kashima Seamount observed during Leg 3 of the first phase of the Kaiko project carried out with the R/V Jean Charcot in 1984 (after the Kaiko I Research Group, 1986). (a): Observed data at the sea surface, (b): upward continued to 1 km, (c): upward continued to $2 \mathrm{~km}$, (d):upward continued to $5 \mathrm{~km}$.

linear least square inversion and suppress noise data, we have applied three upward continuation filters to the grid data to increase input observation data given to the inversion for convenience. The results are shown at altitudes of $1 \mathrm{~km}, 2 \mathrm{~km}$ and $5 \mathrm{~km}$, respectively (Figs. 5(b)-(d)).

The map of the total magnetic field (Fig. 5(a)) shows large amplitudes from $-727 \mathrm{nT}$, minimum, to $+480 \mathrm{nT}$, maximum. It is superimposed on anomalies corresponding to the magnetic lineations of the Pacific plate, the general trend of which is about $\mathrm{N} 75^{\circ} \mathrm{E}$ (Kobayashi et al., 1987). The age of the seafloor beneath Daiichi Kashima Seamount is about $130 \mathrm{Ma}$ from the extrapolation of magnetic lineations identified by Nakanishi et al. (1989). This dating is consistent with the age of oldest fossils (upper Barremian, $\sim 125 \mathrm{Ma}$ ) dredged from the top portion of Daiichi Kashima Seamount by the Research Group for DaiichiKashima Seamount of Tokai University (1985).
In the real application, the topographic data area was expanded broader than the magnetic one to suppress edge effects due to a digital terrain model. The mapping area of the topography, using source data J-EGG500 by the Japan Oceanographic Data Center, is $100 \mathrm{~km}$ by $100 \mathrm{~km}$ as shown in Fig. 4 and grid spacing $2.5 \mathrm{~km}$ after the manner of the magnetic one. We set up unknown medium parameters to be common to 4 by 4 blocks in each layer, that was $10 \mathrm{~km}$ by $10 \mathrm{~km}$, in order to decrease unknowns in linear equations (see Fig. 6). With reference to the result by Ueda (1985), the crustal structure was divided into three layers, which were from minimum depth of studied area to $5 \mathrm{~km}$ depth, $5 \mathrm{~km}$ to $6.5 \mathrm{~km}$ depth and $6.5 \mathrm{~km}$ to $8 \mathrm{~km}$ depth as shown in Fig. 7, to evaluate differences among the top portion of the eastern half part of Daiichi Kashima Seamount (Layer 1), the lower part and the submerged western half part of the seamount (Layer 2), and the upper oceanic crust (Layer 3). 
Figure 8 indicates the results of the inversion: magnetic intensities, horizontal components and inclinations. The root mean square of residuals between observations and calculations was $5.2 \mathrm{nT}$. In these results, simple running mean filters having a widow size of 4 by 4 blocks were applied, whose size corresponded to the area defined by common unknown parameters in the inversion. The horizontal components are shown at every 2 grids $(5 \mathrm{~km})$, and the inclinations are shown only within areas having magnetizations over $2 \mathrm{~A} / \mathrm{m}$. Figure 9 shows a comparison between the observation applied the upward filter of $1 \mathrm{~km}$ (Fig. 5(b)) and the calculation at the altitude of $1 \mathrm{~km}$ based on the results by the inversion. We can see the good agreement between the both anomalies.

Layer 1 Magnetizations of the top layer of Daiichi Kashima Seamount are about $2 \mathrm{~A} / \mathrm{m}$ or less. Ones beneath the continental slope and the top layer of Katori Seamount are also very weak.

Layer 2 Magnetizations of the lower part of Daiichi Kashima Seamount are about 3 to $5 \mathrm{~A} / \mathrm{m}$ in the eastern half part and about $2 \mathrm{~A} / \mathrm{m}$ or less in the western half part and the northwest side of it. Horizontal components indicate that declinations are almost northward directions and inclinations are about $15^{\circ}$ in the lower part of Daiichi Kashima

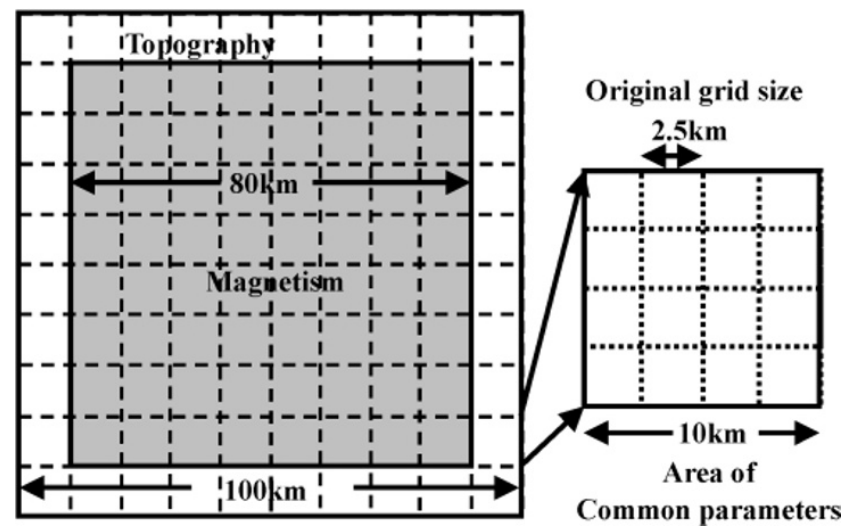

Fig. 6. Topographic and magnetic data areas for the inversion. The topographic data area $(100 \mathrm{~km}$ by $100 \mathrm{~km})$ was broader than the magnetic one $(80 \mathrm{~km}$ by $80 \mathrm{~km})$ to suppress edge effects due to a digital terrain model. Grid spacing was $2.5 \mathrm{~km}$ for both data. Unknown medium parameters were set up to be common to 4 by 4 blocks in each layer, that was $10 \mathrm{~km}$ by $10 \mathrm{~km}$, in order to decrease unknowns in linear observation equations.
Seamount. On the other hand, magnetizations of Katori Seamount are very weak as same as its top layer.

Layer 3 High magnetization areas over $5 \mathrm{~A} / \mathrm{m}$ are revealed on and eastern sides of the trench axis. Especially, the southern and northern sides of Daiichi Kashima Seamount present high magnetizations. In the oceanic crust just beneath this seamount, it is shown that declinations and inclinations correspond to those of the middle layer. In the southeastern and northern sides of Daiichi Kashima Seamount and around Katori Seamount, the reverse magnetizations are recognized in horizontal components. The eastward vectors were originated by running mean filters.

Figure 10 shows a cross section of the magnetic structure along the line $a-b$ indicated in Fig. 4. We can see that the top portion and the submerged western half of Daiichi Kashima Seamount are covered with the low magnetization layers on the average, however, it is recognized that the magnetization in the western scarp side of the top portion is high in comparison with one in the eastern side. In the lower part of this seamount, it is clear that high magnetizations are revealed as was stated previously.

\section{Discussions and Conclusions}

Ueda (1985) indicated that the magnetization vector defined by declination and inclination of the lower part of Daiichi Kashima Seamount (5.25-7 km depth in the eastern part and $6.5-8 \mathrm{~km}$ in the western part) were $-12^{\circ}$ and $20.1^{\circ}$, respectively, and the intensity $10.7 \mathrm{~A} / \mathrm{m}$. For Katori Seamount, he suggested that the lower part $(4.75-7.5 \mathrm{~km}$ depth) had the reversal magnetization. Ishikawa and Den (1984) also analyzed the data by Tokai University. In their results, the shape of magnetic body was similar to the model by Ueda (1985), but the bottom of the body was assumed to be constant at $8 \mathrm{~km}$ depth and declination, inclination and intensity were $6.8^{\circ}, 14.5^{\circ}$ and $4.2 \mathrm{~A} / \mathrm{m}$, respectively. They also reported that basaltic rock samples dredged at the westward scarp of Daiichi Kashima Seamount showed an average magnetic intensity of $5 \mathrm{~A} / \mathrm{m}$.

Our inversion resulted that declinations, inclinations and intensities were almost northward, $15^{\circ}$ and $3-5 \mathrm{~A} / \mathrm{m}$, respectively, in the lower part (5-6.5 km depth) of the eastern half side of this seamount. Intensities of 3-5 A/m obtained in this study are in general agreement with the result by Ishikawa and Den (1984) and the average magnetic intensity $(3.53 \mathrm{~A} / \mathrm{m})$ of the Western Pacific guyots (Nakanishi

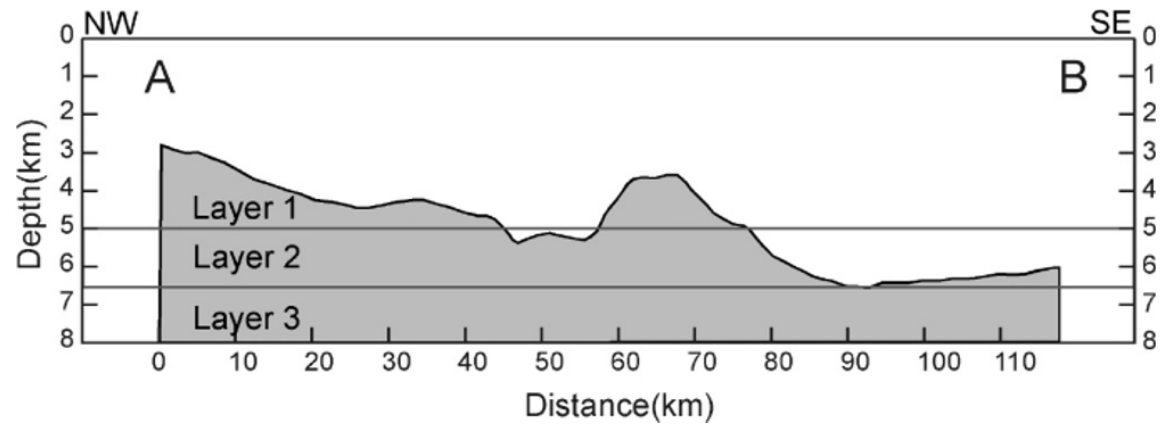

Fig. 7. Definition of layered crustal model. The line A-B is shown in Fig. 4. 

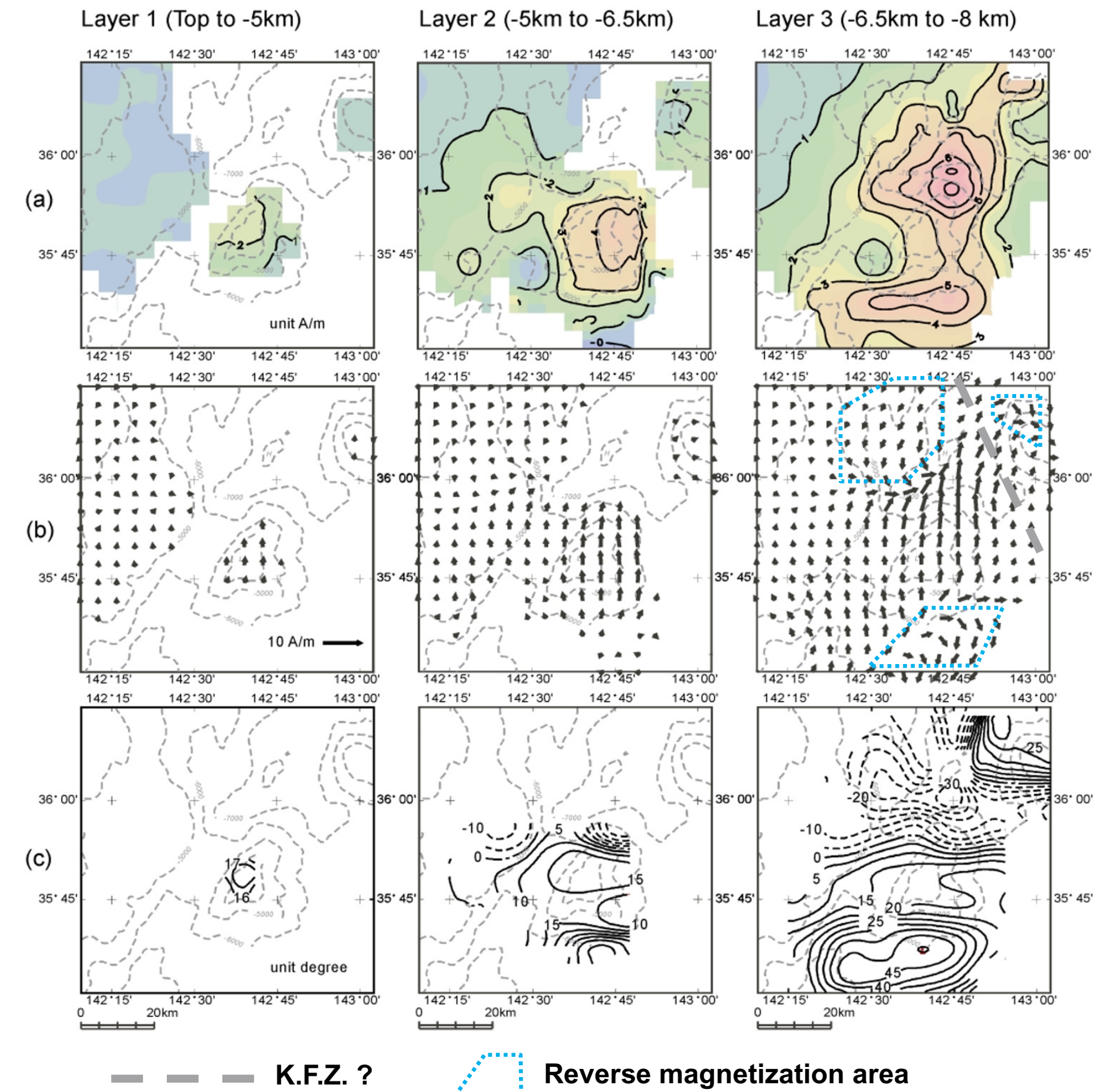

Reverse magnetization area

Fig. 8. Results of the inversion. (a): magnetizations, (b): horizontal components, (c): inclinations. K.F.Z: Kashima Fracture Zone, shaded zone: reverse magnetization areas.

and Gee, 1995; Gee and Nakanishi, 1995). The intensity of $10.7 \mathrm{~A} / \mathrm{m}$ by Ueda (1985) is high as compared with our results and Ishikawa and Den (1984). In the model by Ueda, the bottom of the magnetic body in the eastern half part was assumed to be $7 \mathrm{~km}$ depth, which was shallower than that of Ishikawa and Den. It is considered that the high intensity was caused by the assumption of such small magnetic body.

The inclination of almost $15^{\circ}$ obtained in this study is coincident with results by Ishikawa and Den (1984) and Ueda (1985). On the assumption of geocentric axial dipole and the high Konigsberger's ratio Q, under which the induced magnetization can be neglected, the paleolatitude is calculated to be $7.6^{\circ} \mathrm{N}$. On the other hand, Daiichi Kashima
Seamount, which is located at $35.75^{\circ} \mathrm{N}, 142.67^{\circ} \mathrm{E}$ and is inferred to be upper Barremian age, $\sim 125 \mathrm{Ma}$ (the Research Group for Daiichi-Kashima Seamount of Tokai University, $1985)$, is supposed to be formed at $1^{\circ} \mathrm{S}, 165^{\circ} \mathrm{W}$ based on the absolute plate motion model of the Pacific plate by Koppers et al. (2001). The discrepancy between two paleolatutudes $7.6^{\circ} \mathrm{N}$ and $1^{\circ} \mathrm{S}$ suggests that the geomagnetic equator has been biased toward the south latitude as compared with the present one during the formation of Daiichi Kashima Seamount.

The reverse magnetizations in the third layer were revealed in the southeastern and northern sides of Daiichi Kashima Seamount and around Katori Seamount. The mag- 

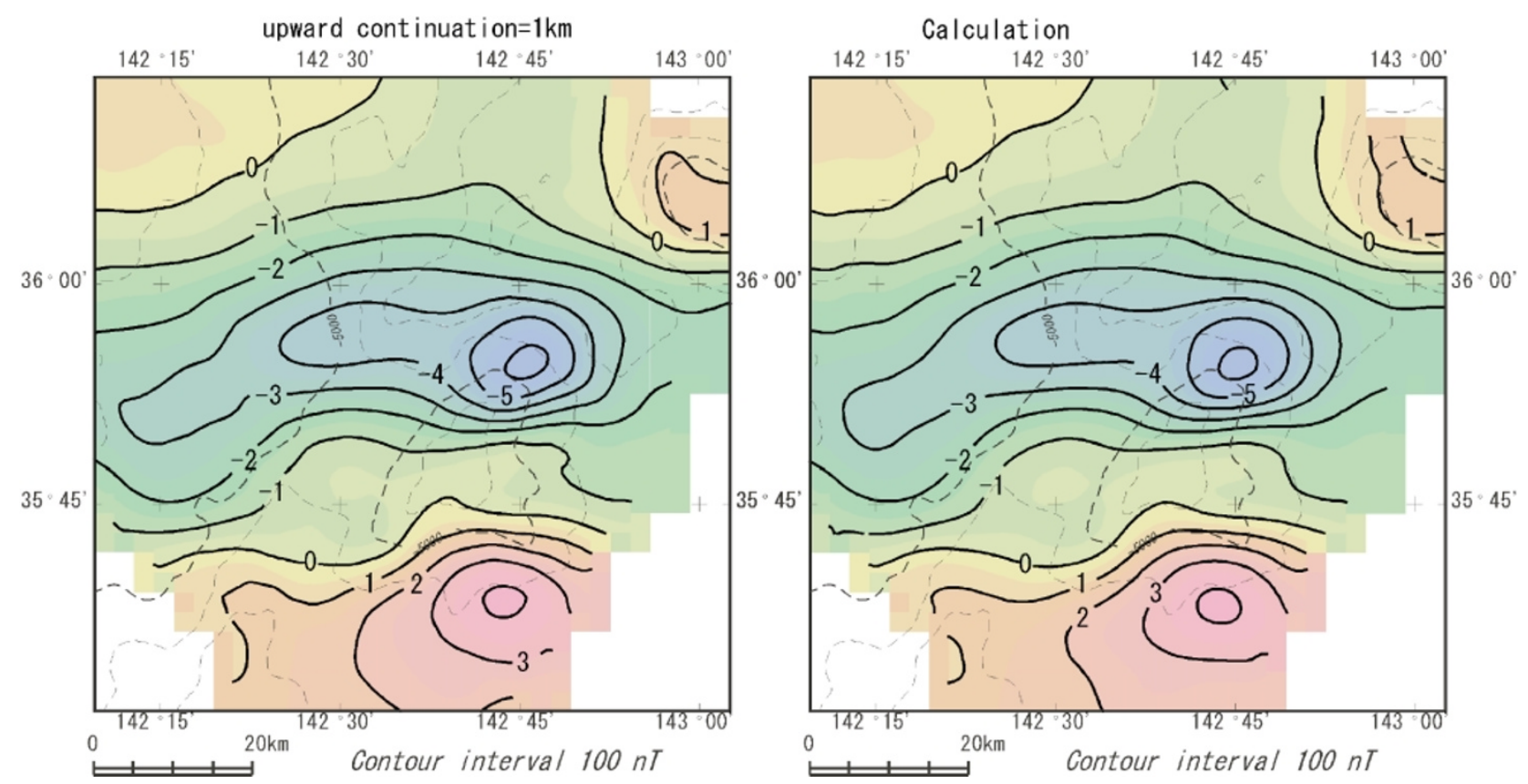

Fig. 9. Observation applied the upward filter of $1 \mathrm{~km}$ (Fig. 5(b)) and the calculation at the altitude of $1 \mathrm{~km}$ based on the results in Fig. 8 by the inversion.

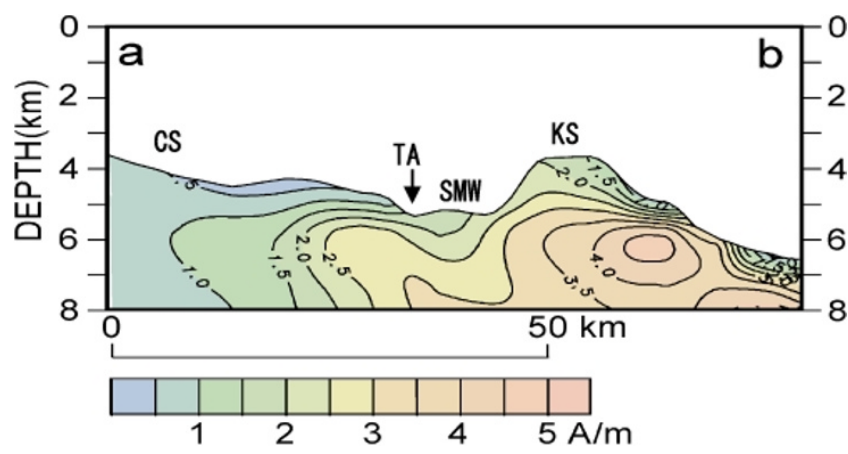

Fig. 10. Cross-section of magnetizations by the inversion. The line a-b is shown in Fig. 4. TA : Trench axis, KS : Daiichi Kashima Seamount, SMW : The submerged western half part of Daiichi Kashima Seamount, CS : Continental slope.

netization of the third layer shows somewhat complicated features in comparison with the magnetic lineations in the Western Pacific. This may partly due to the shallow bottom depth of the middle layer (5-6.5 km depth) which should be extended to the depth of $7 \mathrm{~km}$ as modeled by Ueda (1985). The reverse magnetization of Katori Seamount has already been pointed by Ueda (1985). These reverse magnetizations may reflect part of the magnetic lineations of the Pacific plate. It is also recognized that those in the northern side of Daiichi Kashima Seamount do not continued to the reversal magnetized part of Katori Seamount as shown in Fig. 8. It appears that this magnetic discontinuity indicates a tectonic line in the northern end of the Kashima Fracture Zone proposed by Nakanishi (1993).

In general, our results in this study are consistent with other studies. The method proposed in the present study is useful to analyze magnetic properties of a seamount objectively and to separate superimposed magnetic anomalies into each magnetic property originated by a seamount and the magnetic lineations.

Acknowledgments. We would like to acknowledge Kaiko I Research Group, who furnished us with the data of the Kaiko-project. We wish to thank Dr. Y. Ueda of JHOD for his critically reading the manuscript and giving many valuable suggestions. We also thank Prof. H. Fujimoto and Dr. M. Nakanishi for their useful comments and suggestions. We are grateful to Dr. A. Oshida for help with the calculation of the absolute motion model of the Pacific plate.

\section{References}

Bhattacharyya, B. K., Magnetic Anomalies due to prism-shaped bodies with arbitrary polarization, Geophysics, 29, 517-531, 1964.

Bjorch, A. and T. Elfving, Accelerated projection methods for computing pseudo inverse solutions of systems of linear equations, BIT, 19, 145163, 1979.

Gee, J. S. and M. Nakanishi, Magnetic petrology and magnetic properties of western Pacific guyots: implications for seamount paleopoles, Proc. ODP Sci. Results, 144, 615-630, 1995.

Ishikawa, H. and N. Den, Analysis of geomagnetism of Daiichi-Kashima Seamount, Proc., SEGJ Conference, 71, 102-103, 1984.

Kaiko I Research Group, Topography and structure of trenches around Japan, Data of the Franco-Japanese Kaiko Project, Phase I, 305 pp., Ocean Res. Inst. Tokyo, 1986.

Kobayashi, K., J. P. Cadet, J. Aubouin, J. Boulegue, J. Dubois, R. Huene, L. Jolivet, T. Kanazawa, J. Kasahara, K. Koizumi, S. Lallemand, Y. Nakamura, G. Pautot, K. Suyehiro, S. Tani, H. Tokuyama, and T. Yamazaki, Normal faulting of the Daiichi-Kashima Seamount in the Japan Trench revealed by the Kaiko I cruise, Leg 3, Earth Planet. Sci. Lett., 83, 257-266, 1987.

Koppers, A. A. P., J. P. Morgan, J. W. Morgan, and H. Staudigel, Testing the fixed hotspot hypothesis using ${ }^{40} \mathrm{Ar} /{ }^{39} \mathrm{Ar}$ age progressions along seamount trails, Earth Planet. Sci. Lett., 185, 237-252, 2001.

Kubota, R., Y. Ueda, and K. Onodera, On the method of the three dimensional geomagnetic inversion, Proc., SEGJ Conference, 104, 309-313, 2001.

Le Pichon, X., K. Kobayashi, J. P. Cadet, T. Iiyama, K. Nakamura, G. Pautot, V. Renard, and the Kaiko Scientific Crew, Project KaikoIntroduction, Earth Planet. Sci. Lett., 83, 183-185, 1987.

Mogi, A. and K. Nishizawa, Breakdown of a seamount on the bottom of the Japan Trench, Proc. Japan Acad., 56(5), Ser. B, 1980.

Nakanishi, M., Topographic expression of five fracture zones in the North- 
western Pacific Ocean, Geophysical Monograph, 77, 121-136, 1993.

Nakanishi, M. and J. S. Gee, Paleomagnetic investigations of volcanic rocks of LEG 144 volcanic rocks: Paleolatitudes of the northwestern Pacific guyots, Proc. ODP Sci. Results, 144, 585-604, 1995.

Nakanishi, M., K. Tamaki, and K. Kobayashi, Mesozoic magnetic anomaly lineations and seafloor spreading history of the northwestern Pacific, $J$. Geophys. Res., 94, 15437-15462, 1989.

Parker, R. L., L. Shure, and J. A. Hildebrand, The application of inverse theory to seamount magnetism, Review of Geophysics, 25, 17-40, 1987.

Research Group for Daiichi-Kashima Seamount of Tokai University, Daiichi-Kashima Seamount, pp. 79-100, Tokai University Press, 1985.

Talwani, M., Computation with the help of a digital computer of magnetic anomalies caused by bodies of arbitrary shape, Geophysics, 30, 797$817,1965$.

Ueda, Y., Geomagnetic study on Seamounts Daiiti-Kasima and Katori with special reference to a subduction process of Daiiti-Kasima, J. Geomag. Geoelectr., 37, 601-625, 1985.

Ueda, Y., H. Nakagawa, K. Onodera, A. Suzuki, K. Kumagawa, and R. Kubota, 3D-geomagnetic structure of Miyake-jima Volcano before the eruption in 2000: an application of 3D-geomagnetic tomography method, Rept. Hydrogr. Res., 37, 19-36, 2001 (in Japanese with English abstract).

Vacquier, V., A machine method for computing the magnetization of a uniformly magnetized body from its shape and a magnetic survey, pp. 123137, Benedum Earth Magnetism symposium, University of Pittsburgh Press, Pittsburgh, Pa., 1962.

R. Kubota (e-mail: kubotar@kge.co.jp) and A. Uchiyama 